\title{
Urban Art and place. Spatial patterns of urban art and their contribution to urban regeneration
}

\author{
María Laura Guerrero Balarezo, Kayvan Karimi \\ Space Syntax Lab, Bartlett School of Architecture, University College London UCL. UK \\ E-mail: maria.balarezo.16@ucl.ac.uk,k.karimi@ucl.ac.uk
}

\begin{abstract}
Cities face several challenges regarding public space and urban regeneration. Some of them are the depersonalization and lack of interest of citizens in their own city, privatization, gentrification, technologization and gender-insecurity. Public spaces lose their character as articulator and generator of human relations, while in neighborhoods lose their role as the basic unity of community and urban identity. Nowadays, many bottom-up strategies have arisen as manifestations of neighborhoods inhabitant's will that produce cultural diversity and civic engagement, with a placemaking effect. Urban art is one of them. While social and economic products of urban art have been studied, the spatial manifestation and impact of art has been largely absent from the discourse of urban morphology. Spatial conditions in cities are not just representational of social practices like art, but form and perpetuate these practices through structuring patterns of movement, encounter and separation in the city (Cartiere \& Zebracki, 2016). This study aims to discover the spatial relation between urban art display and the network of public spaces, and whether this pattern has a role in neighborhood regeneration. Using Space Syntax analysis and spatial clustering combined with a survey of geographically located public urban art (extracted from social networks data), land prices and land uses in Shoreditch, London, relations between urban art, the spatial layout and regeneration processes will be stablished. Further research can look at other bottom-up strategies for regeneration and relate them to the urban form.
\end{abstract}

Keywords: Urban Art, urban regeneration, placemaking, spatial analysis

\section{Introduction}

Cities face several challenges when it comes to public space. One of them is the depersonalization and lack of interest of citizens in their own city. It has been said that the design of modern cities has undermined their capacity to support a vital public culture (Goheen, 1998). Other problems observed are privatization (Kohn , 2004), technologization and gender-insecurity (Gumpert \& Drucker, 1994). Public spaces then start losing their character as articulator and generator of basic human relations.

Many strategies have risen as a response to this scenario. Some driven by government, others by citizens, some large scale, some smaller scale. A term has come up to name small scale strategies to increase citizen's enhancement: Tactical Urbanism.

Tactical Urbanism is a bottom-up approach to neighborhood building and activation using short-term, low-cost, and scalable interventions and policies. Tactical Urbanism is used by a range of actors, including governments, business and nonprofits, citizen groups, and individuals. It allows immediate reclamation, redesign and appropriation of public space. This vision, from the local, helps cities and citizens together explore a new form of citymaking, one 
that can envision long-term transformation but also adjust as conditions inevitably change. The power of Tactical Urbanism lays in being able to create tactile proposals for change instead of plans or computer-generated renderings that remain abstract. (Lydon \& Garcia, 2015).

One of the currents in of Tactical Urbanism is Public Urban Art, understood as any form of art manifested in public space. Arts-based Placemaking is an integrative approach to urban planning and community building that stimulates local economies and leads to increased innovation, cultural diversity, and civic engagement. Since creativity fuels place value, the benefits of using arts and culture to tap into a place's unique character extend well beyond the art world. (Project for Public Spaces, 2015).

'Street art creates shared narratives between people, ideas, and the city. Street artists are actively engaging in place-making activities (...) Value and meaning are not inherent in space or place; instead they are continuously created, reproduced, recreated, and defended' (Conklin, 2012)

But, before being used as a tool in placemaking processes, public art is a manifestation in and on itself. In urban terms, art has a part on genderization, politization and commodization of cities. The city, in this view, is a sociological entity consisting purely of patterns of social relations. This is not at all wrong, but it is incomplete. The spatial manifestation and impact of art has been largely absent from the discourse of urban morphology (the study of the shape and layout of urban form). Spatial conditions in cities are not just representational of social practices like art, but form and perpetuate these practices through structuring patterns of movement, encounter and separation in the city (Cartiere \& Zebracki, 2016). To summarize, both public art as a phenomena on itself and as a tool for regeneration have not been analyzed in total depth in spatial terms. Understanding public art from both perspectives can lead to a better understanding of how people live and appropriate of their cities.

\section{Graffiti and Urban Art}

For nearly 50 years researchers have investigated graffiti culture worldwide, and it is pertinent to say that the process of analyzing artistic practices is difficult because it attempts to create order from arbitrariness and what constitutes art is fundamentally subjective (Conklin, 2012). In those terms, it can be said that modern graffiti has many origins. Some say even prehistoric

'Early humans were drawn to express themselves by drawing on cave walls, producing the first evidence of guerrilla art. People have always felt the need to share and express themselves in a public way, sometimes by telling a story or posing a question, many times by presenting a political ideology' (Smith 2007, 11) in (Visconti, Jr, \& Borghini, 2010)

More recently, from the late 1960s, street writing became popular amongst young people in Philadelphia and New York. In 1971 the New York Times published a story on graffiti that helped spreading it to other cities. The relation of graffiti to the Hip Hop movement and certain manifestations of culture like music videos helped launching it globally. (Honing \& MacDowall, 2016).

\section{Urban Art Classification}

The distinctions between classes of public art can vary as much as scholars who work on the subject. There are no agreements, not from the most formal art market positions, nor from the artists, many of who are not even recognized as such, even if they are considered professionals (Klein, 2016). For example, Visconti, Jr \& Borghini, (2010) mention 6 categories: tags (nicknames and signatures), highly stylized writing, sticking (pasting drawings and symbols in public spaces, stencil, poetic assault (writing of poetry on public spaces) and urban design (aesthetic practice practiced to improve public architecture and urban style). Some of these categories have to do with the technique involved in making the work of art, others, like urban design, have a rather ambiguous definition. Honing \& MacDowall (2016) speak about a distinction between graffiti (words and tags) and street art, which focuses on images, often with a political edge and also familiar topics from mainstream culture (like celebrity faces and advertising icons).

For the purposes of this research, four 
categories of urban art will be established: tags and signatures (regardless of how highly stylized them might be). It is worth saying that tags usually come in a cryptic language, easily understood only by those within the movement. However, the importance of tags lays in the fact that is the primary way of engagement with the city that the artist can make: to notice a place and to put a mark of presence on it. The second category would be murals (also known as public art or street art), as drawings of a certain complexity with a more common pictorial language for transmitting a message. The use of color and a more common iconography make this type of art more "digestible" for the general public. The third category would be sculptures, as any form of expression in public space that has depth or requires a third dimension. The fourth and last category are pre-printed papers, whether they have a political stand or a graphic. These is a faster, less risky way of engagement for the artist. Nevertheless, papers have a certain presence within the art scene.

\section{Urban Art as a creative tool for placemaking and regeneration}

Street art has the ability to cause reactions, given that the public always has an opinion about an artwork's existence, message, and artistic value, amongst others. Whether it is to support or condemn the act, the important thing is that it causes a reaction. Rafael Schacter (2008) calls this property of street art agency, defined as 'the ability to capture, hold and transform cognitive operations of its spectators and participants' (Conklin, 2012).

Many scholars nowadays speak about culture-led regeneration (Evans, 2005; Tavano Blessi, Tremblay, Sandri, \& Pilati, 2012; Treskon, 2015), tactical urbanism (Landry, Greene, Matarasso, \& Bianchini, 1996; Lydon \& Garcia, 2015) and creative placemakig (Borrup, 2016). All these currents refer to a form of engaging with the city and building a sense of place from the citizen's perspective. Public art can take part in these movements, given art's property to capture attention and to produce sensations, it becomes a mechanism of relation of both, artists and spectators, to the city. Moreover, Stevens (2007) points that one of the fundamental functions of public space is being a setting for informal social play, which is largely neglected aspect of urban experiences and comprehends activities that are "spontaneous, irrational or risky, and which are often unanticipated by designers, managers and other users' (Stevens, 2007). Spontaneity and risk are both aspects related to the practice of graffiti and street art. To follow with the inherent value of art as argument, art's provocative, challenging and inconvenient nature make it useful to transform perspectives, create new narratives, and ultimately, to support urban resilience by bringing issues of social justice, social cohesion and social equality to the table (Goethe Institut, 2014, 20).

It is necessary to consider all sides of an aspect, in respect to art as a tool for regeneration. The presence of art and artists in a neighborhood has been linked to urban regeneration and community-enhancing processes, but also to gentrification. Ley (1996) affirms that urban artists are 'colonizing arms' of the middle classes, identifying and revalorizing de-valorized inner-urban residential zones through cultural capital and aesthetic contributions (Cameron \& Coaffee, 2005). These revalorized areas then become attractive to young professionals and finally become highly attractive to a class with higher economic capital, that ends up destroying the character of what was initially valorized by the artist (Cameron \& Coaffee, 2005).

Finally, street art and graffiti have an internal logic to function and community is also built amongst artists. Klein (2016) speaks about the friendship between artists, who bond working on things that not necessarily relate to mural interventions, which makes sharing a wall much more than to paint together for a photo. Furthermore, respect and territory are important for graffiti practice, both gained as the painter 'marks' harder locations with his work.

\section{Urban art as a crime}

The propagation of graffiti produced moral panic and fear of crime. Those who oppose graffiti cite the broken windows theory, which states that allowing minor misdemeanors encourages more serious crime and a downward spiral of urban decay because visual 
disorder (e.g., graffiti, broken windows, public intoxication, trash, abandoned cars, etc.) create an atmosphere that attracts criminal offenders, who assume that residents are indifferent about their neighborhood (Conklin, 2012; Link \& Sampson, 2017). Although the theory has never been proven with quantifiable evidence, and nowadays that vision is changing and graffiti is being revalorized, some stigmas still remain.

In the United Kingdom, graffiti and wall painting are treated as a crime. The law understands as graffiti any inscription, marking, writing, painting or drawing, illicitly scratched, scribbled, drawn, cut, carved, posted, pasted sprayed or painted on any surface. Under the Criminal Damage Act 1971 (CDA 1971) and the Clean Neighborhoods and Environment Act 2005 (CNEA 2005), sentences for graffiti range from a conditional discharge from the magistrates' court for minor damage, to up to 10 years imprisonment by the Crown Court where the damage caused is more than $£ 10,000$. To try to avoid being punished, artists must be careful of the time and place where they paint. With the years some strategies have risen, like painting commissioned by the owners of a building, or in the frame of organized festivals, or with companies that mediate between owners and artists. Although some mechanisms exist, there is still no legal structure to protect painters. In this perspective, it remains unclear how urban artists behave in spatial terms. In a research made by (Friedrich, Hillier, \& Chiaradia, 2009) the term 'Anti-social behavior' ASB was applied to many incidents that can be described as sub-criminal, the authors found that ASB can be correlated to physical syntactical properties of the environment, in relation to movement and intervisibility. However, it remains to be seen how graffiti and public art particularly behave.

\section{Methodology}

The study is based in London. The process has been divided in two phases. The first phase points towards understanding the spatial behavior of urban art and graffiti within the urban grid. The second stage aims to relate the presence of art with economic and social factors that can be linked to urban neighborhood regeneration. Hence, three main questions drive this research

What is the spatial relation between the display of urban art and the urban grid?

Are there any spatial patterns?

What is the role of urban art in neighborhood regeneration?

For the spatial behavior of urban art, Space Syntax methods were used to relate art display patterns to the internal properties of the urban grid by assessing the relation of urban art with Integration (centrality) and Choice (betweeeness) measures with the street segment as the unit for observations. Considering the current state of graffiti and urban art as a crime, the initial hypothesis that was attempted to prove is.

There is a topological logic in the display of urban art that takes place somewhere away from the most integrated streets.

To assess the role of urban art with neighborhood regeneration, Treskon (2015) proposes a methodology to evaluate the impact of art projects in a community through the improvement of social and economic outcomes. Some of this measures were taken into account for this study, aggregating them to the unit of analysis, and statistical correlations between the variables were performed, to stablish the relation between them. The variables considered to assess regeneration are prices paid per property (flats sold in the area of study, which are the most popular type of property in the area), land uses related to art (art galleries, museums, community and cultural centers, book stores, theaters, cinemas, restaurants bars, cafes and night life), and crime rates (anti-social behavior, burglary, robbery and vehicle crimes). It is hypothesized that:

There is a positive relation between the quantity of land uses related to art per street segment, prices paid art presence

There is a negative relation between the presence of art and the incidence of crime 


\section{Data collection}

\section{FLICKR API}

Online social networking and sharing services have generated large volumes of spatiotemporal information about the physical environment and social phenomena ( $\mathrm{Li}$, Goodchild, \& Xu, 2013). 'Nowadays, a substantial part of the available social media data has a geographical component, in which locations are stored in the form of a geotag or as a textual description' (Drift, 2015). In order to trace urban art concentrations in London, geo-located points were downloaded using the FLICKR API under certain parameters for analysis, allowing to make use of available data at a big scale to study a social phenomenon with a spatial manifestation. The parameters used were the following:

Photos taken from 01/01/2014 to 31/12/2016 The photos had the tags urban art, street art, public art and graffiti

Points were downloaded with a radius of $3 \mathrm{~km}$ from the point

Lat: 51.5212106 Long: -0.0740046 , close to the center of London to allow to assess the state and spatial distribution of public art at an urban scale.

This social network platform was chosen for having an open-data policy and a user-friendly API, which make it easy to access and use information. To narrow down the amount of information to begin studying the phenomena, it was decided to work with the most recent situation of urban art, which is why the data corresponding to 2016 was chosen for analysis. On-site Survey of Urban Art

In order to assess downloaded data, and also to have more precision on the location of the points that allowed a more in-depth analysis, a survey of the existing situation of urban art was made. During a series of walks through the area of study, using a mobile phone GPS with the app OSM Tracker for Android, that allowed to take pictures and create automatically a GPX file with the points. The GPX file was converted into a GIS shapefile and then edited the points manually to correct location imprecisions that might have been derived from the GPS use. Also, the points were classified according to the literature review, and in some cases (when possible), details about the artists were added.

\section{Data for social and economic outcomes}

The data used for stablishing a relation between urban art and regeneration was obtained from several sources. Land use patterns for the ground floor were downloaded from Google using the Google API, obtaining a set of geolocated points. Property prices per post code and their location were obtained from the HM Open Registry Data services. Crime data with geolocation was obtained from the open datasets of the Metropolitan Police. All these geolocated points were added to the closest street segment for analysis, and all collections of data correspond to the year 2016.

\section{Determining a Case Study Area}

A Kernell Density Map performed with a radius of $800 \mathrm{~m}$ showed clusters of urban art in the city using the FLICKR downloaded points taken in 2016. Based on the clusters, the main and more central cluster corresponded to the Shoreditch area. The limit of the area of study was defined by following the street pattern surrounding the main cluster, leaving out the limit of the City of London. The reason to do this was taking into consideration how the street art phenomena works in the perspective of the interviews performed previously: the City of London is a highly monitored area by police and CCTV, which is why the phenomena wouldn't develop naturally on this space (Figure 1).

\section{Measurement and analysis Spatial Patterns}

\section{Urban Scale}

A segment analysis of Integration radius $n$ was performed and compared to the initial clusters obtained in the Kernell Density map. It showed, in accordance to the literature review, that urban art clusters tangentially touch some of the most integrated lines in the system, however, they are not crossed by them, except for the central cluster that corresponds to Shoreditch. (Figure 2) 


\section{Neighborhood Scale}

At a neighborhood scale, Metric Integration analyses at different radiis were performed $(100,200,400,800,2000 \mathrm{~m})$. The one chosen for deeper analysis was Integration $400 \mathrm{~m}$, because it was the local measure that better related to the pattern displayed in the public art survey.

Then, to follow the hypothesis about a topological phenomenon happening somewhere away from the integration core, a Step Depth analysis was made for both, graffiti and murals from the most integrated line in the system. This analysis showed that $79 \%$ of murals take place 1, 2 and 3 steps away from the most integrated line. It also showed that $92 \%$ of graffitis were located 2, 3 and 4 steps away from the most integrated line in the system. (Figure 3)

After, the points of art that were located over the $50 \%$ highest values of Integration 400 were taken out, leaving still the majority of observations. A scatter plot that presented the relation between Integration 400 values and the graffiti and murals count showed that $96 \%$ of graffitis and $94 \%$ of murals were located in segments with the lowest $50 \%$ of Integration values (Figure 4).

\section{Social and economic outcomes related to regeneration}

The analysis consisted in stablishing a set of relations between the variables. A correlation matrix showed a significant relation, between the concentration of land uses related to art and the presence of murals. There is an interesting correlation between land uses related to art, and Integration measures at 800 and $2000 \mathrm{~m}$ radii. Also, the chosen set of land uses relates significantly to the property prices for flats. As for the relation with crime, the strongest and more significant coefficients were related to the location of land uses as well, and surprisingly, contrary to the initial hypotheses, the relation between crime and land uses is positive. Finally, a relation between the surveyed urban art and the data obtained from FLICKR shows a stronger link with surveyed murals, allowing to presume that what is reflected in social networks is more related to murals than to graffiti. (Figure 5)

Counting from the top of normalized Integration radii $2000 \mathrm{~m}$, which is the one that showed better correlation with land uses, it is worth to note that $50 \%$ of the count of land uses related to art are within the top $79 \%$ of integration. In the same interval, are also $25 \%$ of the murals, only $13 \%$ of the representative values for flats sold, and a variation of 21 to $34 \%$ of the selected crime types. In spatial terms, it means that crime, for example, is not located near the most integrated segments of the layout. I also means that land uses related to art, a type of "cultural economy", have a certain spatial link to the presence of murals in the most integrated segments, a surprising result, given that mural painting is not a legal practice. (Figure 6)

\section{Conclusion}

What the analysis shows in terms of spatial patterns is how urban art is a phenomena that happens slightly away from the most integrated segments of the urban grid, both in local and global scales. The relation with the $400 \mathrm{~m}$ radii also allows to conclude that is something that happens at a pedestrian scale. The fact that murals are found 1,2 and 3 steps away from the most integrated core, while tagging or graffiti manifest 2, 3 and 4 steps away, show a matter of social and public acceptance between what is conceived as urban art. This fact is supported by the statistical correlation between the survey of urban art and the data obtained from the online platform FLICKR. But this also shows a level of acceptance from public perspective to certain kinds of street art, which can be well used for creating public policy towards culture-led regeneration.

As to what refers to social and economic outcomes, the link between land uses related to art and the presence of murals indicates that public art and cultural economy are spatially related as well, which is encouraging when considering these variables from the regeneration perspective. The relatively low relation between integration values and land uses with land prices deserves a deeper look, 


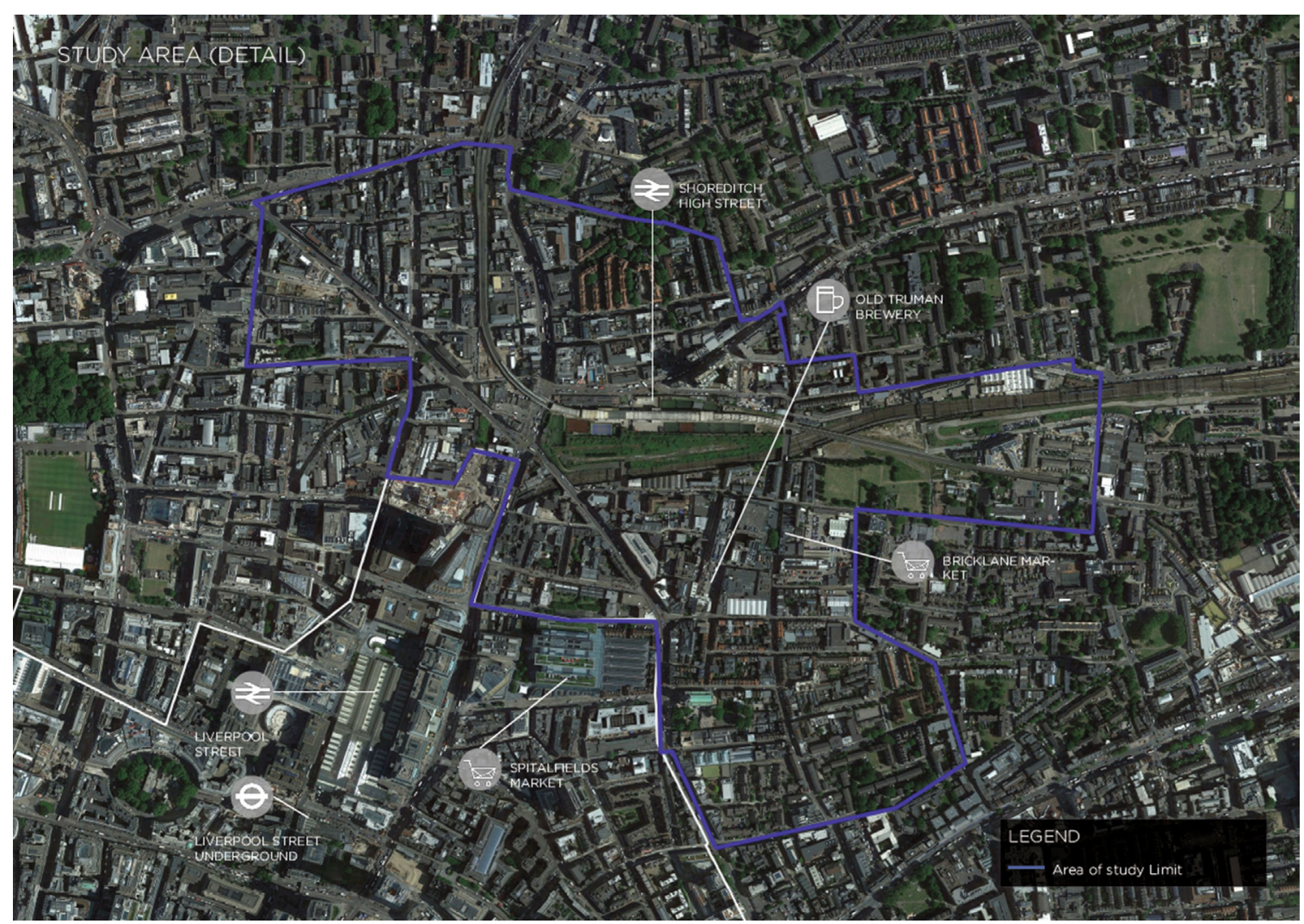

Figure 1. Area of study excluding the City of London to the south-west extreme

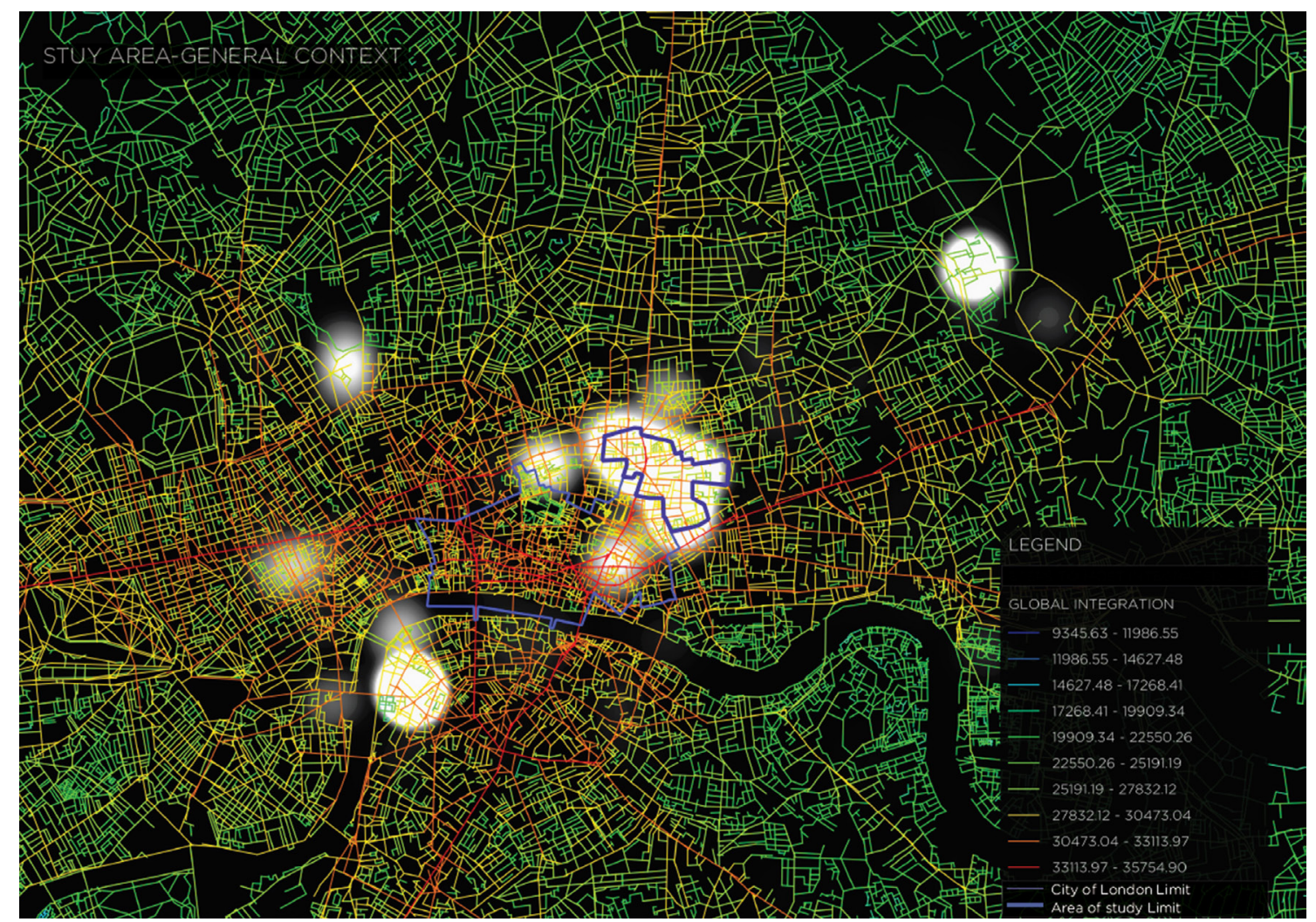

Figure 2. Clusters of art points and Global Integration map, showing how clusters touch the most integrated lines in the system only at the edge. 
STEPS TO THE MOST INTEGRATED LINE GRAFFITI
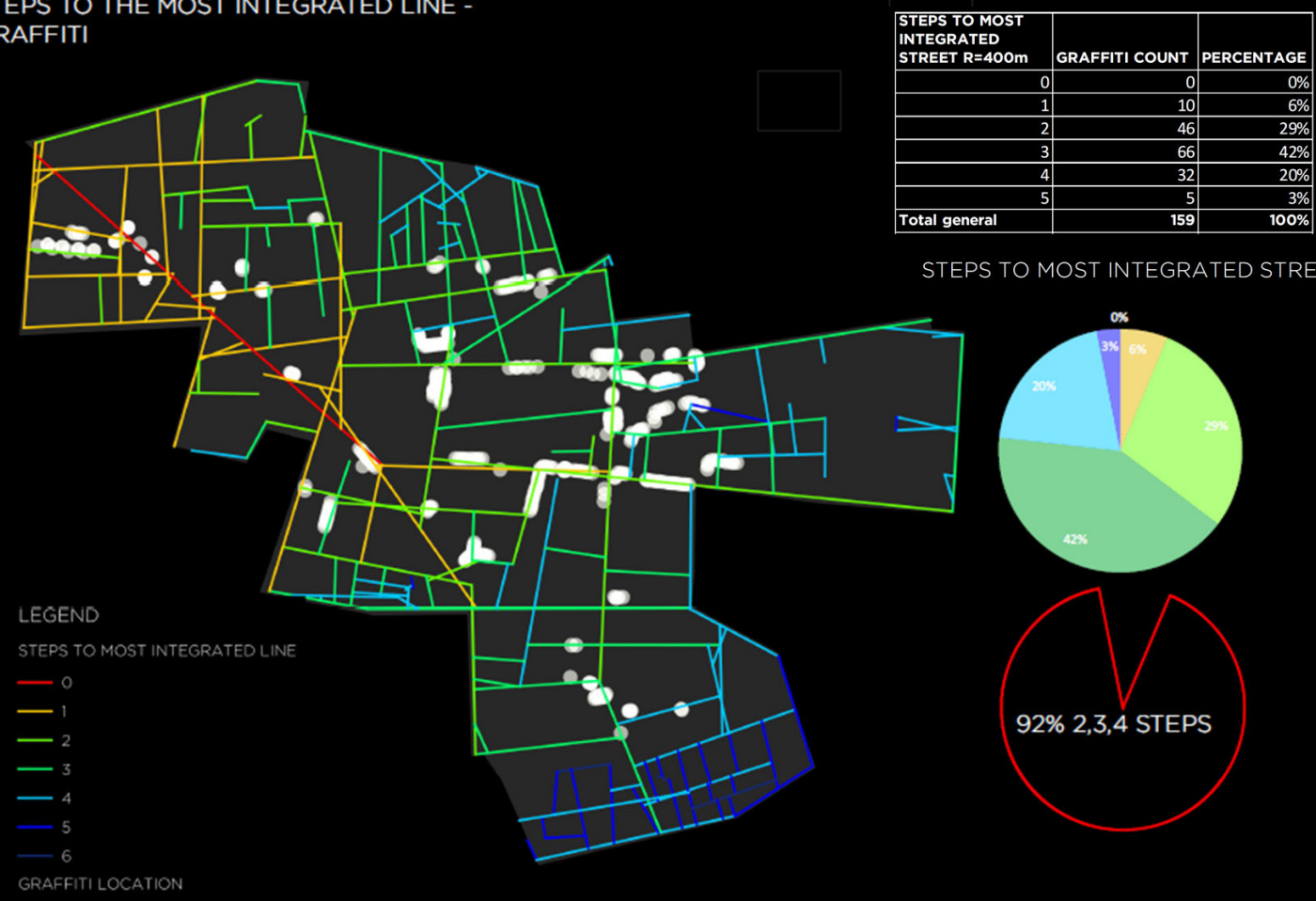

STEPS TO MOST INTEGRATED STREET

- gRAFFITI/TAGS

STEPS TO THE MOST INTEGRATED LINE -

URBAN ART
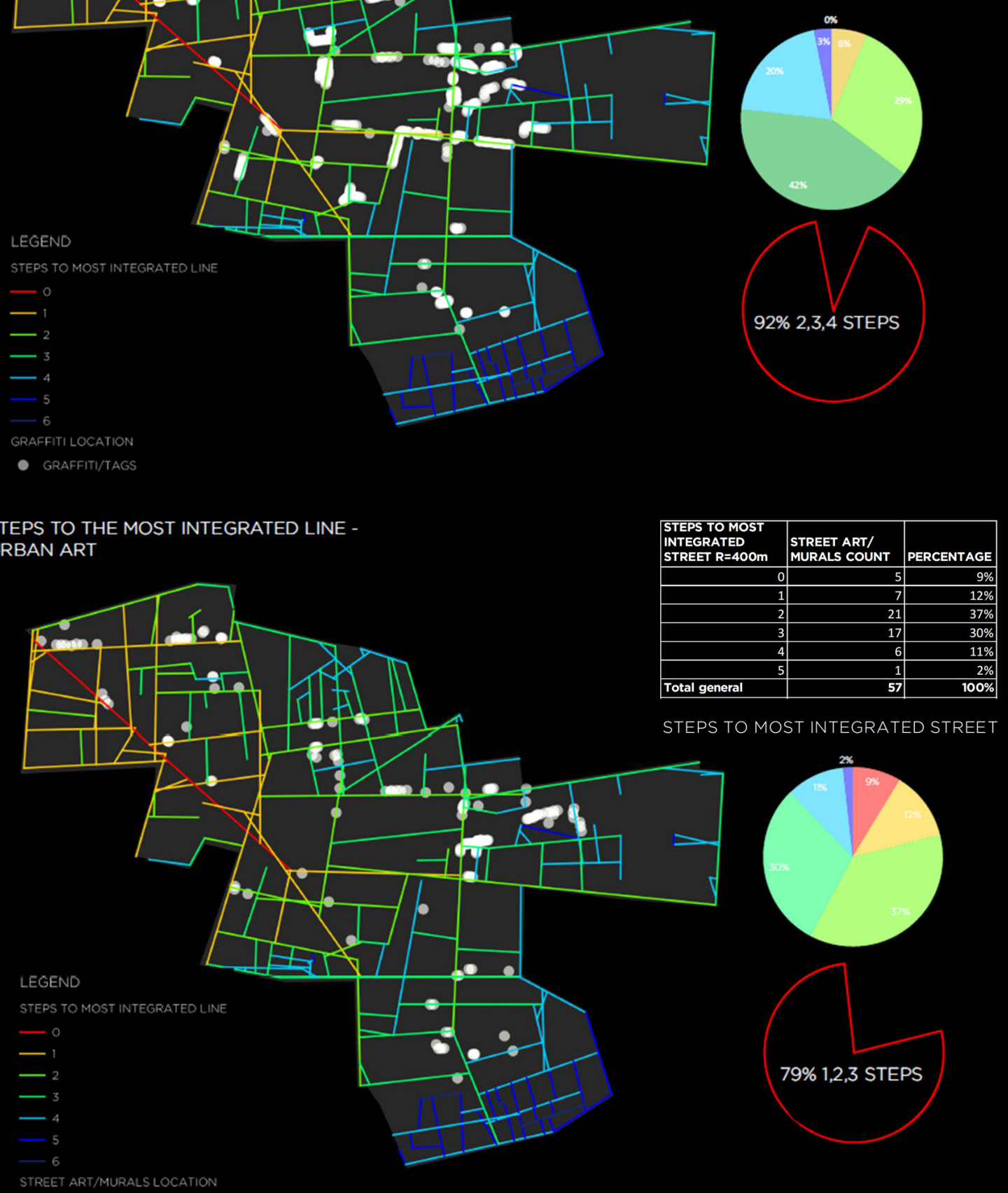

STEPS TO MOST INTEGRATED STREET

- STREET ART/MURALS

Figure 3. Step Depth analysis for graffitis and murals. 

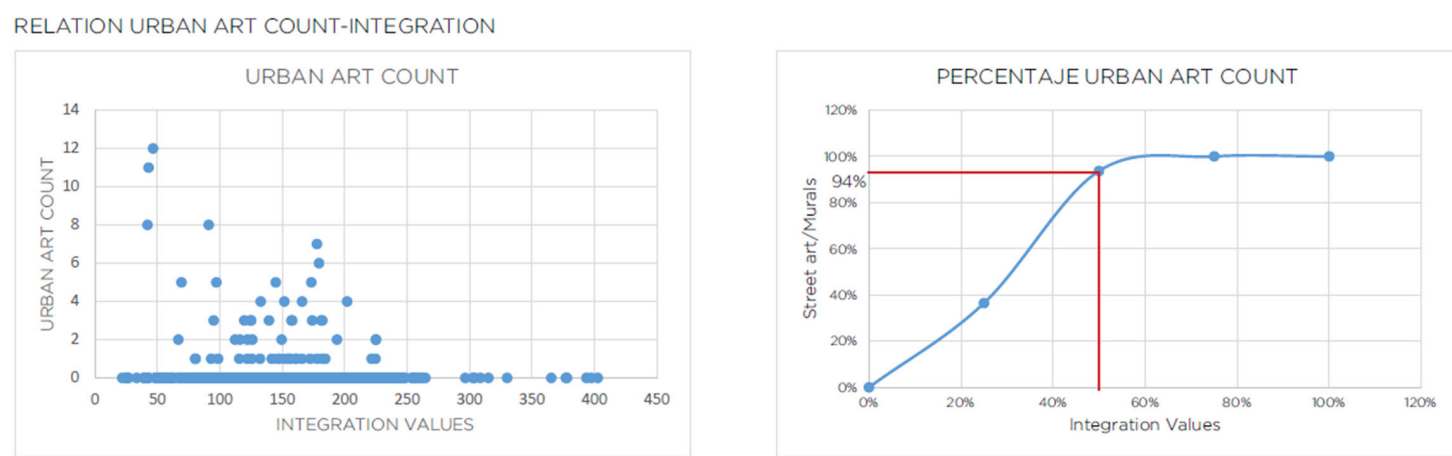

RELATION GRAFFITI COUNT-INTEGRATION
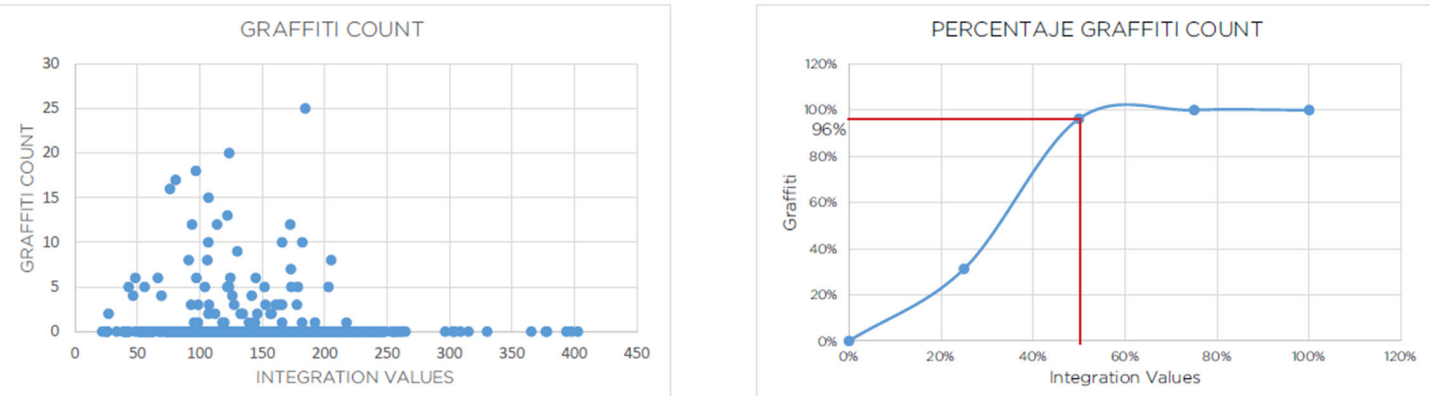

Figure 4. Relation between graffiti counts, public art counts and Integration.

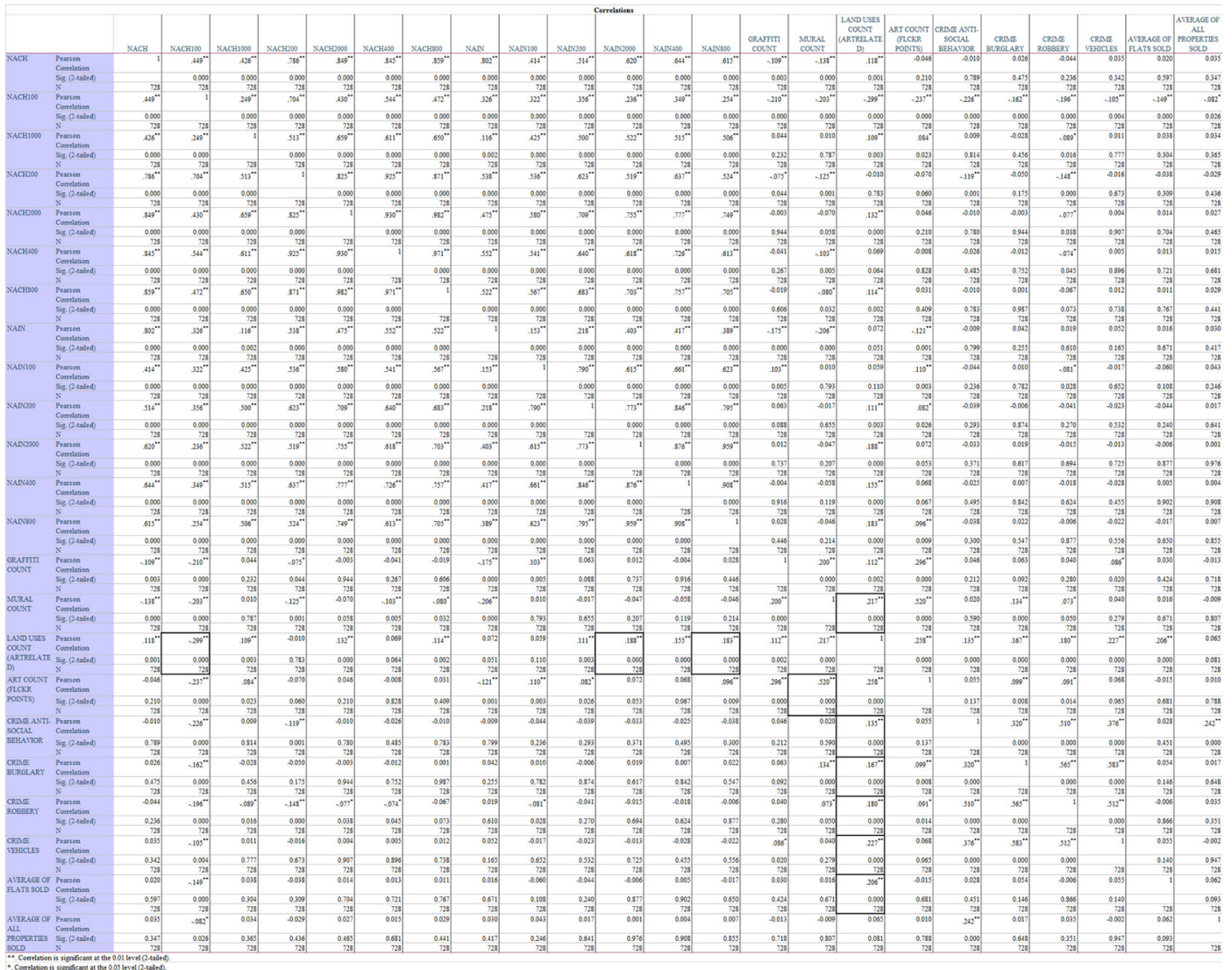

Figure 5. Matrix of correlations for 2016. 


\begin{tabular}{|l|l|r|l|l|l|l|r|}
\hline $\begin{array}{l}\text { Percentage } \\
\text { NAAn 200 } \\
\text { Values }\end{array}$ & $\begin{array}{l}\text { Fercentage Count } \\
\text { Land Uses (Related } \\
\text { to art) }\end{array}$ & $\begin{array}{l}\text { Percentage Count } \\
\text { Murals }\end{array}$ & $\begin{array}{l}\text { Percentage } \\
\text { Average Price } \\
\text { (Flats) }\end{array}$ & $\begin{array}{l}\text { Percentage Crime } \\
\text { Anti-social } \\
\text { Beahvior }\end{array}$ & $\begin{array}{l}\text { Percentage } \\
\text { Crime } \\
\text { Burglary }\end{array}$ & $\begin{array}{l}\text { Percentage } \\
\text { Crime } \\
\text { Robbery }\end{array}$ & $\begin{array}{l}\text { Percentage } \\
\text { Crime Vehicle }\end{array}$ \\
\hline $100 \%$ & $0 \%$ & $0 \%$ & $0 \%$ & $0 \%$ & $0 \%$ & $0 \%$ & $0 \%$ \\
\hline $84 \%$ & $25 \%$ & $3 \%$ & $13 \%$ & $14 \%$ & $10 \%$ & $8 \%$ & $9 \%$ \\
\hline $79 \%$ & $50 \%$ & $23 \%$ & $13 \%$ & $34 \%$ & $31 \%$ & $20 \%$ & $21 \%$ \\
\hline $71 \%$ & $75 \%$ & $46 \%$ & $46 \%$ & $61 \%$ & $59 \%$ & $48 \%$ & $48 \%$ \\
\hline $40 \%$ & $100 \%$ & $100 \%$ & $100 \%$ & $100 \%$ & $100 \%$ & $10 \%$ & $100 \%$ \\
\hline $0 \%$ & $100 \%$ & $100 \%$ & $100 \%$ & $100 \%$ & $100 \%$ & $100 \%$ & $100 \%$ \\
\hline
\end{tabular}
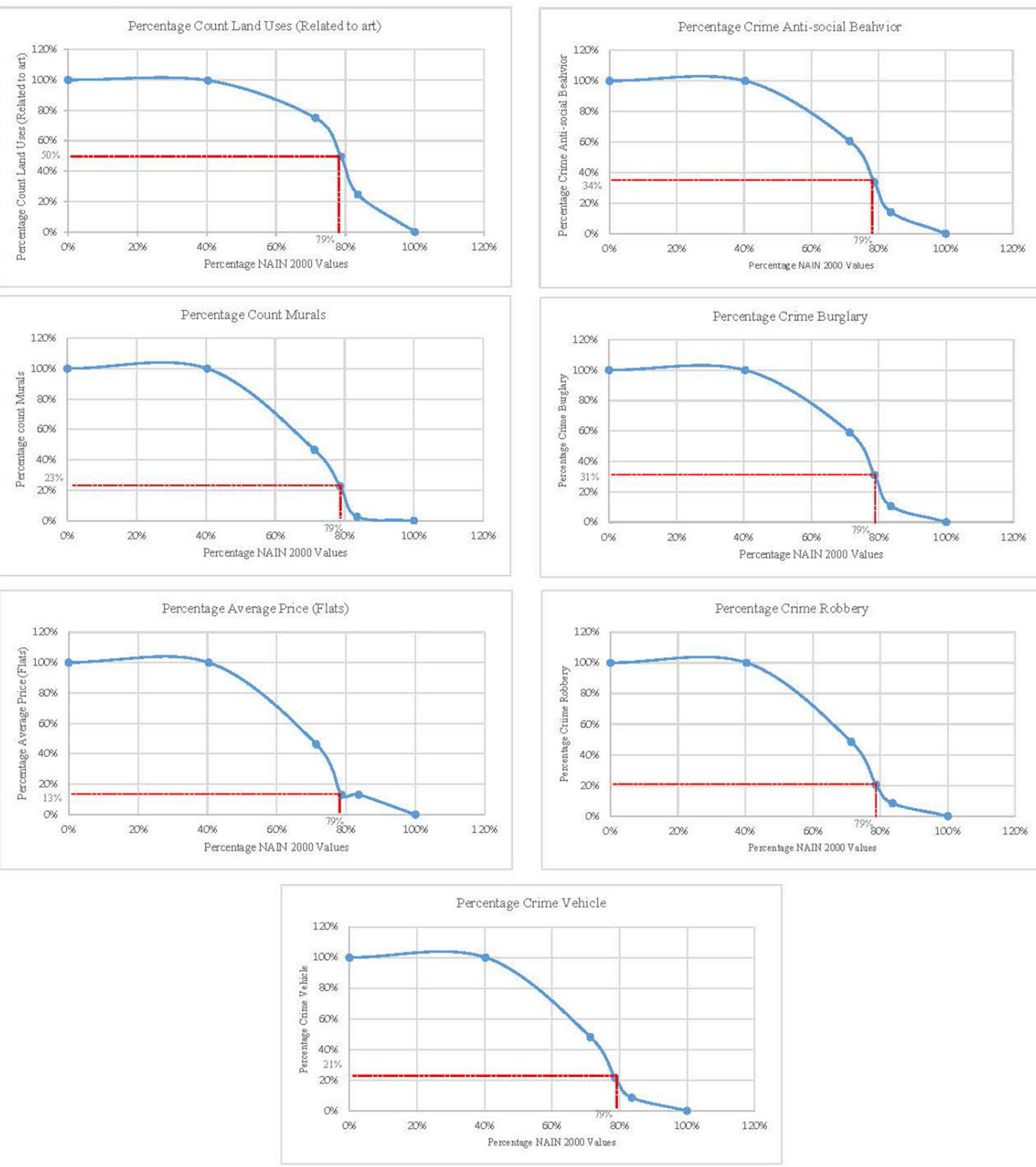

Figure 6. Relation between socio-economic variables and Integration for 2016. 
given the fact that it might seem to contradict what literature often states. As this is a part of an on-going research, a portion of future effort will focus on clarify this effect.

Amongst the lessons learnt during this research, is the need for available open data at a postcode or household disaggregation level, given the fact that some social and economic variables related to regeneration were left out because the available data was found at a larger scale, blurring the depth of analysis that Space Syntax allows at a street segment level.

Future research could look at other bottomup mechanisms related to the urban grid and their dynamic as a regenerative tool. Also, other aspects of urban art could be researched from a spatial perspective, like the message it delivers in terms of political statement or protest.

\section{References}

Borrup, T. (2016). Creative Placemaking: Arts and Culture as a Partner in Community Revitalization. In Fundamentals of Arts Management (pp. 1-22). University of Massachusetts.

Cameron, S., \& Coaffee, J. O. N. (2005). Art , Gentrification and Regeneration -- From Artist as Pioneer to Public Arts, 5(1), 39-58. http://doi.org/10.1080/14616710500055687

Conklin, T. R. (2012). Street Art, Ideology, and Public Space. Portland State University.

Drift, S. Van Der. (2015). Revealing spatial and temporal patterns from Flickr photography. A case study with tourists in Amsterdam. Wageningen Universit.

Evans, G. (2005). Measure for measure: Evaluating the evidence of culture's contribution to regeneration. Urban Studies, 42(5), 959-983. http://doi. org/10.1080/00420980500107102

Friedrich, E., Hillier, B., \& Chiaradia, A. (2009). Anti-social Behaviour and Urban Configuration Using Space Syntax to Understand Spatial Patterns of Socioenvironmental Disorder. In D. Koch, L. Marcus, \& S. Jesper (Eds.), Proceedings of the 7th International Space Syntax Symposium (pp. 1-16). Stockholm.
Goethe Institut. (2014). The Role of Artists \& The Arts in Creative Placemaking. Retrieved from http://www.goethe.de/ins/us/was/pro/ creative_placemaking/2014_Symposium Report.pdf

Honing, C., \& MacDowall, L. (2016). Audience constructed genre with Instagram: Street art and graffiti. First Monday, 21(8), 1-14.

Klein, R. (2016). Creativity and territory: SAUC, 2(2), 6-15.

Landry, C., Greene, L., Matarasso, F., \& Bianchini, F. (1996). The Art of Regeneration: Urban Renewal Through Cultural Activity, 73. Retrieved from http://books.google. com/books?id=vXnHAAAACAAJ\&pgis $=1$

Li, L., Goodchild, M. F., \& Xu, B. (2013). Spatial , temporal, and socioeconomic patterns in the use of Twitter and Flickr. Cartography and Geographic Information Science, 40(2), 61-77.

Link, C., \& Sampson, R. J. (2017). Disparity and diversity in the contemporary city: social ( dis ) order revisited. The British Journal of Sociology, 60(1), 1-31. http://doi. org/10.1111/j.1468-4446.2009.01211.x

Lydon, M., \& Garcia, A. (2015). Tactical Urbanism. Short-term Action for Longterm Change. Washington, D.C.: The Streets Plans Collaborative, Inc.

Stevens, Q. (2007). The Ludic City. Oxon: Routledge.

Tavano Blessi, G., Tremblay, D. G., Sandri, M., \& Pilati, T. (2012). New trajectories in urban regeneration processes: Cultural capital as source of human and social capital accumulation - Evidence from the case of Tohu in Montreal. Cities, 29(6), 397-407. http://doi.org/10.1016/j.cities.2011.12.001

Treskon, M. (2015). Measuring Creative Placemaking. Measuring Livability in the Station North Arts \& Entertainment District, Baltimore. Baltimore.

Visconti, L. M., Jr, J. F. S., \& Borghini, S. (2010). Street Art , Sweet Art ? Reclaiming the "Public" in Public Place, 37(October). http://doi.org/10.1086/652731 